\title{
Role of tumour necrosis factor $\alpha$ in experimental arthritis: separate activity of interleukin $1 \beta$ in chronicity and cartilage destruction
}

\author{
Wim B van den Berg, Leo A B Joosten, George Kollias, Fons A J van de Loo
}

\begin{abstract}
Chronic arthritis is characterised by persistent joint inflammation and concomitant joint destruction. Using murine arthritis models and neutralising antibodies as well as cytokine specific knockout conditions, it was found that tumour necrosis factor $\alpha(\mathrm{TNF} \alpha)$ is important in early joint swelling. Membrane bound TNF $\alpha$ is sufficient to drive this aspect of inflammation as well as the acute cellular infiltrate in the synovial tissue. Interleukin 1 (IL1) is not necessarily a dominant cytokine in early joint swelling, but has a pivotal role in sustained cellular infiltration and erosive cartilage damage. $T N F \alpha$ independent IL1 production is a prominent feature in murine arthritis models. These observations provide evidence for potential uncoupling of joint inflammation and erosive changes, implying that both cytokines need to be targeted to achieve optimal treatment.

(Ann Rheum Dis 1999;58:(Suppl I) I40-I48)
\end{abstract}

Rheumatoid arthritis (RA) is characterised by chronic inflammation of multiple joints and marked destruction of cartilage and bone. The pathogenesis is largely unknown, but RA is generally considered as an autoimmune disease, with primary or secundary involvement of $\mathrm{T}$ cells. However, particular (auto)antigens have not been identified yet, thus hampering specific immunomodulation as a straight forward therapeutic approach. Apart from $\mathrm{T}$ cell involvement, evidence is accumulating that the inflammatory process in the synovial tissue is dominated by activated monocytes and fibroblasts. ${ }^{1}$ Cytokines and cytokine inhibitors derived from these cell types can be abundantly found and dominant cytokines do provide another, approachable target in this disease. It is now commonly accepted that tumour necrosis factor $\alpha(\mathrm{TNF} \alpha)$ and interleukin 1 (IL1) are pivotal mediators in the RA process. ${ }^{23}$ Moreover, the arthritogenic potential of $\mathrm{TNF} \alpha$ is elegantly demonstrated by the occurrence of a chronic, destructive joint inflammation in transgenic mice, displaying overexpression of human $\mathrm{TNF} \alpha .{ }^{4}$ Clinical trials revealed that TNF neutralisation provides substantial relief of RA symptoms, such as pain and number of swollen joints. So far it is unclear whether anti$\mathrm{TNF} \alpha$ treatment also reduces cartilage and bone erosions. Although IL1 blocking with IL1 ra did not yield clear improvement of clinical symptoms, data from the first clinical trial ${ }^{5}$ provided evidence of amelioration of joint erosions, and this suggests that IL1 is a crucial target as well.

Given the poor regenerative capacity of cartilage, it is unethical to take cartilage biopsy specimens in early stages of human arthritis and this seriously hampers proper evaluation of efficacy of anti-cytokine treatment in RA patients on erosive processes. Markers of cartilage destruction have been developed, but proper evaluation of progression of damage in RA patients is still a moot point. At least a number of consecutive measurements are needed, markers often reflect both increased breakdown as well as increased synthesis and the amount of cartilage, which is still present in the joint is another major determinant. Breakdown markers are not expected to be high when the joint is already largely destroyed. Detailed studies in animal models of arthritis are therefore of crucial importance in further understanding of mechanisms underlying cartilage destruction, and identification of feasable ways of cartilage and bone protective therapy. In the following sections emphasis will be given to recent findings in cytokine interplay in murine arthritis models, with particular attention to distinct roles of TNF $\alpha$ and IL1 $\beta$. Apart from the inflammatory process in the joint, major attention is given to aspects of cartilage and bone destruction.

\section{Cartilage destructive cytokines}

Articular cartilage is an acellular tissue, consisting of chondrocytes embedded in a highly structured matrix. Proteoglycans and collagen type II are the major macromolecules in this tissue, providing tensile strength and load bearing capacity. Cartilage destruction in chronic arthritis is characterised by two major events: reduced synthesis of matrix components by the articular chondrocytes as well as increased breakdown of cartilage matrix, by enzymes originating from cartilage itself and/or the inflamed synovial compartments. Early changes identified in experimental arthritis models include proteoglycan loss, with concomitant denuding of the tight collagen meshwork. This event makes the matrix vulnerable to advanced damage. A major step in erosive tissue loss in articular cartilage is the destruction of collagen bundles. Apart from enzymes released from synovial cells, increased breakdown of cartilage may result from cytokine activation of chondrocytes.

When the presently identified cytokines are considered, it is clear that both TNF $\alpha$ and IL1 can cause cartilage damage in vitro, ${ }^{6}$ but IL1 is
Geert Grooteplein Zuid 8,

$6500 \mathrm{HB}$ Nijmegen, the

Netherlands. 
much more potent, with proven efficacy in vivo. ${ }^{7}$ In principle, no difference in potency was noted between the two isoforms of IL1: IL $1 \alpha$ and IL $1 \beta$. It is believed that IL $1 \alpha$ is a major cytokine in early stages of inflammation, whereas IL $1 \beta$ is the more dominant cytokine in advanced inflammation. Although $\mathrm{TNF} \alpha$ is far less potent, it is noteworthy that TNF may display considerable synergism with $\mathrm{IL} 1{ }^{8}$ More recently, IL17 and Oncostatin $M$ have been identified as cartilage destructive cytokines. IL17 is a T cell derived cytokine, which has been demonstrated in RA synovial tissue. ${ }^{9}$ Oncostatin $\mathrm{M}$ is also produced in considerable amounts by RA synovium. Relative potency, IL $1 / T N F \alpha$ dependent production and potential synergism with the IL $1 / \mathrm{TNF} \alpha$ system have yet to be determined.

Apart from initial studies of local, intraarticular injection of recombinant forms of IL $1,{ }^{7}$ overexpression of IL1 has now been achieved by local gene transfer in the rabbit knee joint, demonstrating a full blown arthritis. ${ }^{10}$ In addition, transgenic mice overexpressing IL1 $\alpha$ also display full signs of a destructive inflammatory arthritis. ${ }^{11}$ Both studies emphasise that IL1 alone can elicit the major manifestations of arthritis. Intriguingly, it was shown by elegant studies in TNF transgenic mice that $\mathrm{TNF} \alpha$ overexpression leads to chronic arthritis, ${ }^{4}$ yet treatment with antibodies to the IL1 receptor fully abolished the arthritic process. ${ }^{12}$ Remarkably, TNF levels were still high in these animals, excluding a direct destructive effect of $\mathrm{TNF} \alpha$ alone, in vivo, and further substantiating a dominant role of IL1.

\section{Murine models of arthritis}

Although the above data illustrate the potency of cytokines in single mediator systems, their actual role remains to be identified in accepted arthritis models, using the approach of neutralising antibodies, soluble receptors or cytokine specific knockout mice.

In line with current thinking of the RA process, the models should reflect conditions of $\mathrm{TNF} \alpha$ dependent joint inflammation. This may be driven by $\mathrm{T}$ cells stimulation or by direct activation of macrophages with environmental stimuli such as bacteria or viruses. Alternatively, chronic joint inflammation could be the end result of impaired regulation of $\mathrm{TNF} \alpha$ production. ${ }^{13}$ As RA is a disease that occurs at older age, a genetic disturbance of $\mathrm{TNF} \alpha$ production as the sole underlying mechanism is unlikely, and excessive exposure to environmental stimuli, and/or loss of proper regulation of tolerance seems more obvious.

In this paper studies will be described in two types of models. Firstly, allergic joint inflammation, directed against protein (auto)antigens in the joint and driven by $\mathrm{T}$ cells and immune complexes; secondly, macrophage driven disease, caused by local activation in the joint with phlogistic stimuli such as persistent bacterial cell wall fragments.

The model most widely studied in arthritis research is the autoimmune collagen induced arthritis (CIA), which is based on immunisation with foreign collagen type II in genetically susceptible mice, mainly $\mathrm{DBA} / 1 \mathrm{j}$ or $\mathrm{B} 10 \mathrm{RIII}$ mice. It examplifies an autoimmune process against an autoantigen in the articular cartilage. The arthritis expression is dependent on a mixture of anti-collagen type II antibodies and anti-CII Th1 cells, with dominant involvement of Th1 lymphocytes. ${ }^{14}{ }^{15}$ The polyarthritis starts around four weeks after the first immunisation against collagen type II, usually in a limited number of joints, with gradual spreading to multiple joints. The expression can be facilitated by systemic injection of $\mathrm{TNF} / \mathrm{IL} 1$ or indirect generation of such mediators by induction of non-specific inflammatory events around the time of expected onset. ${ }^{16}$ The controlling role of endogenous IL10 and the clear arthritis promoting role of IL $12^{17}$ argues that bacterial infections may facilitate expression of smouldering autoimmune joint inflammation.

\section{Role of TNF $\alpha$ and IL1 $\beta$ in collagen arthritis}

Kinetic analysis showed abundant expression of TNF $\alpha$ and IL1 $\beta$ in the synovial tissue of affected joints, for a number of days after onset of arthritis. ${ }^{18}$ When anti-TNF $\alpha$ antibodies or soluble receptors are given before or shortly after onset of first signs of arthritis, marked amelioration of joint inflammation was demonstrated by various groups. ${ }^{19}{ }^{20}$ The scoring of inflammation was done by analysis of outer signs of inflammation in the paws. The TNF $\alpha$ dependence of the arthritis expression is encouraging, reflecting similarity with cytokine dependence of this parameter in RA patients. We have compared the efficacy of TNF $\alpha$ and IL1 blocking in this model, including a kinetic study starting anti-cytokine treatment at various days after onset of arthritis. It confirmed that TNF blocking is effective in early stages. However, less efficacy is noted in established disease (fig 1). In contrast, the suppressive effect of IL1 elimination was more pronounced and also prominent in established arthritis. ${ }^{21} 22$ RT-PCR analysis of synovial tissue made it clear that IL1 expression was greatly increased in the synovial tissue and articular cartilage, and was at least as high as compared with TNF $\alpha$ expression. IL1 $\beta$ appeared more important as compared with IL $1 \alpha$, as selective blocking with antibodies to IL1 $\beta$ was almost as effective as blocking with anti-IL $1 \alpha+$ antiIL1 $\beta$. Moreover, marked suppression of arthritis was demonstrated in IL $1 \beta$-converting enzyme (ICE) deficient mice, lacking the enzyme involved in IL1 $\beta$ processing, and pronounced suppression of collagen arthritis can be achieved with ICE inhibitors. ${ }^{23}$

The role of IL1 was further substantiated with IL1ra (receptor antagonist) treatment. This antagonist is known for its poor pharmacokinetics and appeared highly effective in experimental models, only when applied with osmotic minipumps. ${ }^{21} 22$ IL1 signalling occurs already with $2 \%$ receptor occupancy and sustained, high levels of inhibitor are mandatory to block IL1 receptor binding. In our hands attempts to block collagen arthritis with repeated injections of high doses of IL1 ra were 

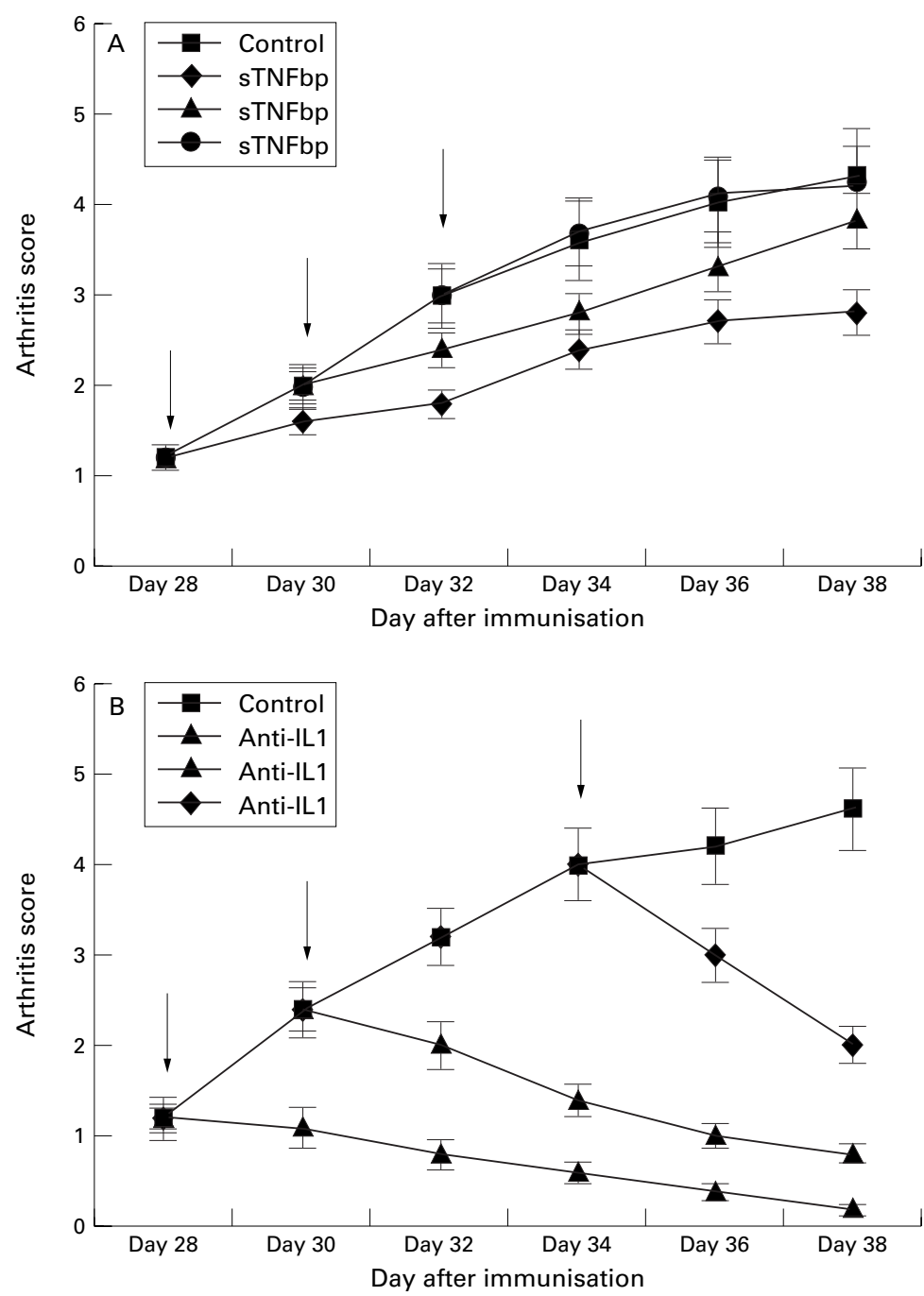

Figure 1 Treatment of collagen arthritis with TNF binding protein or anti-IL1a+ $\beta$ antibodies, starting at various days after onset of arthritis (arrows). Note the loss of effect in established disease with TNFbp and the continued effect of anti-IL1 (see also references 22 and 30). disturbed generation of immune responses. ${ }^{26} 27$ An elegant alternative has been provided by the recent studies in TNF-receptor1 deficient mice, crossed to DBA/1. These mice show normal lymph node architecture. Upon immunisation with CII these mice developed CIA with a lower incidence and in a milder form. However, once a joint was afflicted the arthritis progressed in that joint to the same end stage as observed in the wild type mice. ${ }^{28}$ This again argues that $\mathrm{TNF} \alpha$ is important at onset, but that progression is TNF $\alpha$ independent. Along the same line, it may suggest that anti-TNF treatment in RA patients may be beneficial, when chronicity of the disease is in fact based on repeated, acute episodes, with each flare displaying TNF dependency.

\section{VARIABILITY IN FINDINGS IN COLLAGEN ARTHRITIS}

Variation in claimed efficacy of anti-TNF $\alpha$ treatment in chronic stages of this model is noted in various laboratories. Obvious reasons for this might include variable susceptibility to and expression of this autoimmune disease in $\mathrm{DBA} / \mathrm{j}$ mouse strains in different animal facilities, as well as variation in stringency of immunisation protocols to break natural tolerance to collagen type II, all of this potentially linked to variation in the degree of $\mathrm{T}$ cell and immune complex involvement. TNF $\alpha$ is important in $\mathrm{T}$ cell activation, but immune complex arthritis appeared strongly IL1 dependent. ${ }^{29}$ Immune complexes are a crucial element in the facilitation of expression of collagen arthritis. IL1 driven cartilage damage with subsequent expression of sufficient collagen type II epitopes may be further elements to skew the arthritis to an IL1 dependent phenotype. In addition to that, when the model is accelerated by non-specific stimuli such as supplementation of cytokines ( $\mathrm{TNF} \alpha, \mathrm{IL} 1)$ or boosting with LPS, synchronised arthritis expression is seen in multiple joints and this will create advanced disease in almost all joints within a week after onset. When spontaneous, non-accelerated expression is analysed, it is obvious that such a protocol will allow initiation of arthritis in some joints, with slow spreading to other joints over a period of weeks. In fact, every new onset in a naive joint is highly $\mathrm{TNF} \alpha$ dependent and cumulative scoring will then show apparent $\mathrm{TNF} \alpha$ dependency of the overall arthritis score in "advanced" stages, even at various weeks after onset of the first signs in other joints.

CARTILAGE DESTRUCTION IN COLLAGEN ARTHRITIS WITH ANTI-TNFa?

When histological samples are taken from joints after treatment with either anti-TNF $\alpha$ or anti-IL1, in our hands anti-TNF $\alpha$ is only providing protection against cartilage destruction, when treatment is started right at the onset. In fact, it is only protective when expression and independent progression of the destructive autoimmune process can be prevented. If treatment with anti-TNF $\alpha$ is started shortly after onset, swelling reduction is still seen but histological examination shows that the reducthat these mice show major abnormalities in lymphoid tissue organisation and may display 


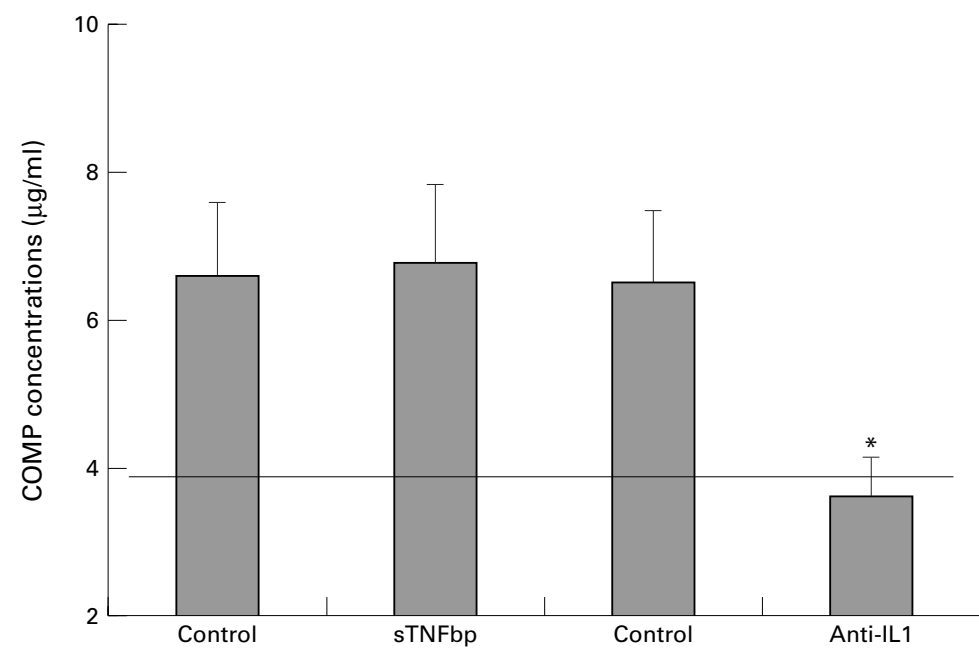

Figure 2 COMP levels in the serum at day 38 of collagen arthritis. After treatment with TNFbp no reduction is seen, whereas reduction to normal levels (line) is observed after anti-IL1a $+\beta$ treatment.

tion of cell influx in the synovium is marginal and cartilage damage is unaffected. ${ }^{22} 30$

Apart from proper histological evaluation, we recently screened levels of COMP (cartilage oligomeric matrix protein) in the circulation of mice with CIA, after treatment with either anti-TNF $\alpha$ or anti-IL1. COMP is a marker of increased turnover of articular cartilage and levels are markedly increased in CIA (fig 2). When anti-TNF $\alpha$ treatment was started after onset of arthritis, we did not observe a reduction in raised COMP levels, and this correlated with lack of protection against cartilage damage on histological sections. In clear contrast, anti-IL1 treatment normalised COMP levels to values found in non-arthritic mice. This underlines great differences in impact of TNF $\alpha$ and IL1 neutralisation on cartilage destruction in this model. ${ }^{30}$ Remarkably, similar findings have been obtained in experimental encephalomyelitis. TNF acceler-

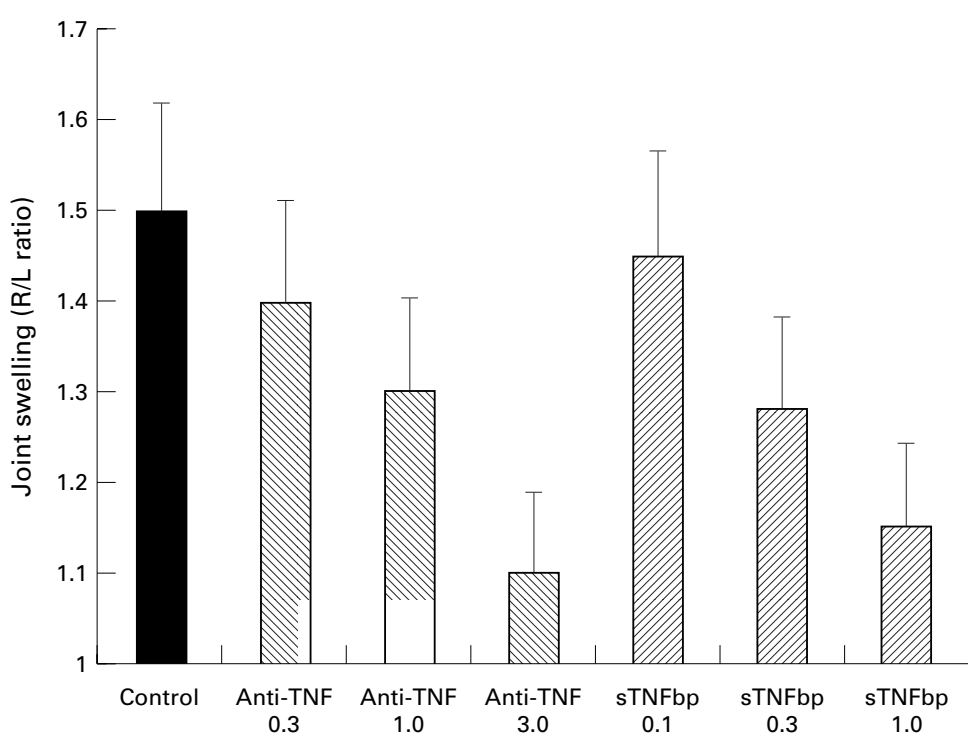

Figure 3 Dose dependent suppression of joint swelling with anti-TNFa or TNFbp. Start of systemic treatment shortly before induction of $S C W$ arthritis, measurements of joint swelling at day 2. (See reference 34 for further reading). ates onset but does not change incidence and severity of the damaging process. ${ }^{31}$

\section{TNF $\alpha /$ IL1 involvement in streptococcal} cell wall (SCW) arthritis

The above data in collagen arthritis suggest that not all IL1 is driven by TNF, as IL1 blocking was more efficacious as compared with TNF blocking, in particular in late stage CIA. This would suggest that anti-TNF $\alpha$ treatment is not sufficient in RA and that combination therapy with anti-IL1 should be mandatory. However, it can still be argued that TNF blocking was not optimal, or that advanced stages of the collagen arthritis model do not reflect the human disease. The first argument is unlikely because studies were performed with high doses of neutralising antibodies as well as soluble TNF binding proteins; the second argument, that RA is a disease process with triggering elements different from CIA, can of course never be excluded.

To get a better impression of general validity of the need of separate TNF $\alpha$ and IL1 blocking, we focused our further studies on the TNF/IL1 involvement in the model of SCW induced arthritis. Bacterial cell walls are potent inducers of $\mathrm{TNF} \alpha$ and in that sense the cytokine pattern in SCW arthritis, after intraarticular injection of cell wall fragments in the murine knee joint, comes close to the clinical situation in RA patients. As differences between in vivo potency of neutralising antibodies or scavenging receptors against $\mathrm{TNF} \alpha$ and IL1 can never be fully excluded, we performed additional studies in $\mathrm{TNF} \alpha$ and IL1 $\beta$ knockout mice.

In SCW arthritis pronounced uncoupling between mediator involvement in joint swelling, synovial infiltrate and cartilage damage is seen. When $\mathrm{TNF} \alpha$ is blocked, using either anti-TNF antibodies or TNF binding protein (engeneered soluble receptor from Amgen), marked dose dependent reduction in joint swelling is found, again underlining the crucial role of $\mathrm{TNF} \alpha$ in this parameter (fig 3). In marked contrast, inhibition of chondrocyte proteoglycan synthesis in the articular cartilage, which is a key event in the articular cartilage in every type of joint inflammation and clearly an IL1 dependent phenomenon, ${ }^{32}$ remained unchanged. Of note, twice daily systemic injections with IL10 mimicked the anti$\mathrm{TNF} \alpha$ effect, in that it reduced joint swelling but did not normalise the synthesis inhibition in the articular cartilage. This is compatible with the findings that IL 10 is a powerful $\mathrm{TNF} \alpha$ inhibitor, but has marginal effects on IL1 production, in vivo. ${ }^{33}$

In sharp contrast, IL1 blocking with neutralising antibodies or IL1 ra did not reduce joint swelling, but fully normalised chondrocyte synthetic function. ${ }^{34}$ Intriguingly, and compatible with ongoing impact on cartilage, $\mathrm{TNF} \alpha$ blocking in vivo did not significantly reduce IL1 levels in the arthritic synovial tissue. ${ }^{34}$ Histological examination at day 7 made it clear that anti-TNF $\alpha$ treatment did not protect against proteoglycan loss from the articular cartilage, whereas this protection was impres- 

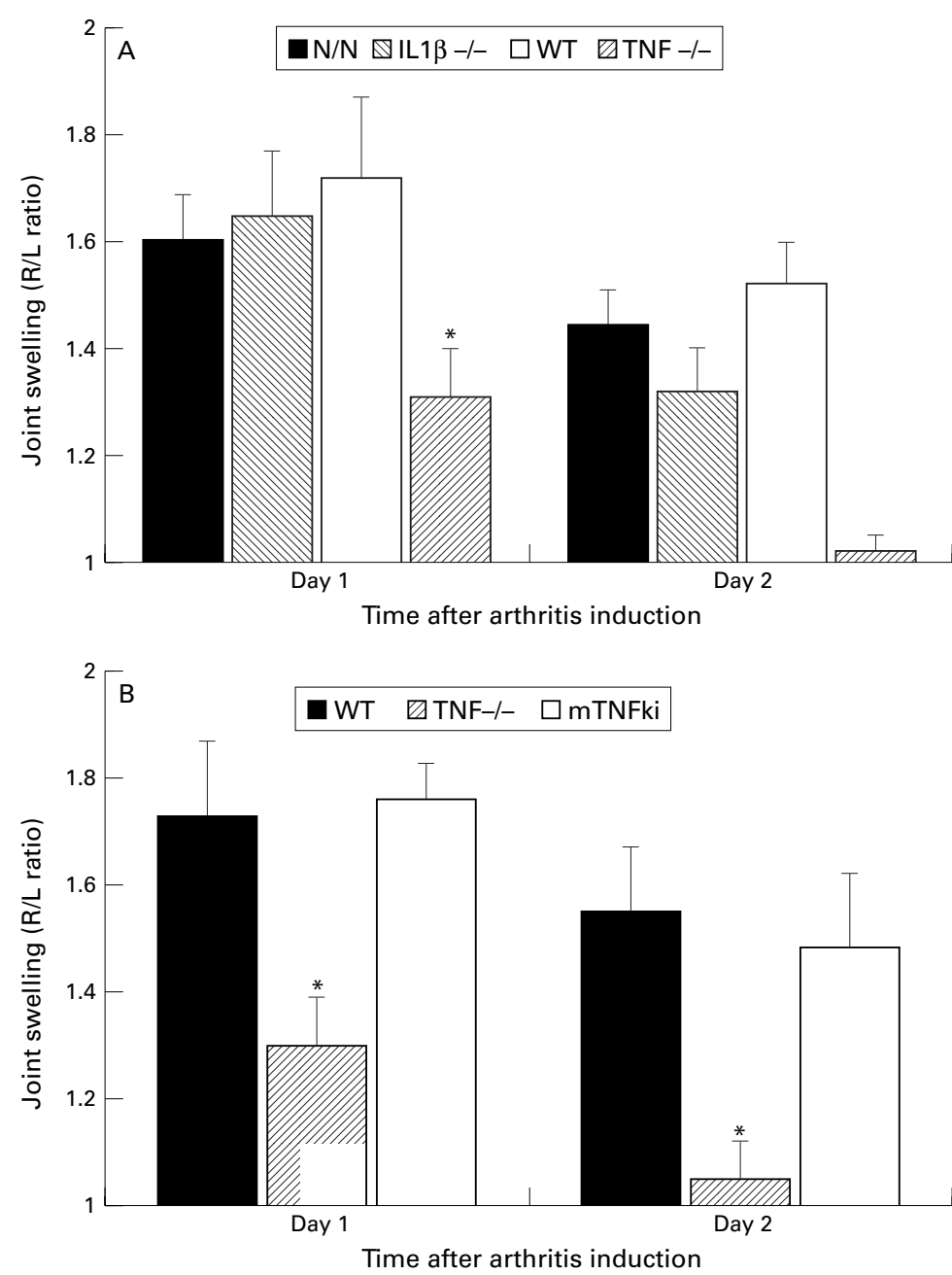

Figure 4 foint swelling at days 1 and 2 after induction of SCW arthritis in knockouts and their respective controls (NN for IL1 $\beta-/-, W T$ for TNFa -/-). Note the TNFa dependency of joint swelling. Similar studies in mTNFki, reflecting knockin of mTNFa in $T N F-/-$ mice, reveal that $m T N F a$ is sufficient to drive swelling.

sive after IL1 blocking. The obvious experiment, combined blocking with anti-TNF $\alpha$ and anti-IL1, did provide the best overall protection in that now both the initial swelling as well as the cartilage damage at day 7 were optimally controlled. However, the protection against cartilage damage was not improved as compared with that achieved with anti-IL1 alone, ${ }^{34}$
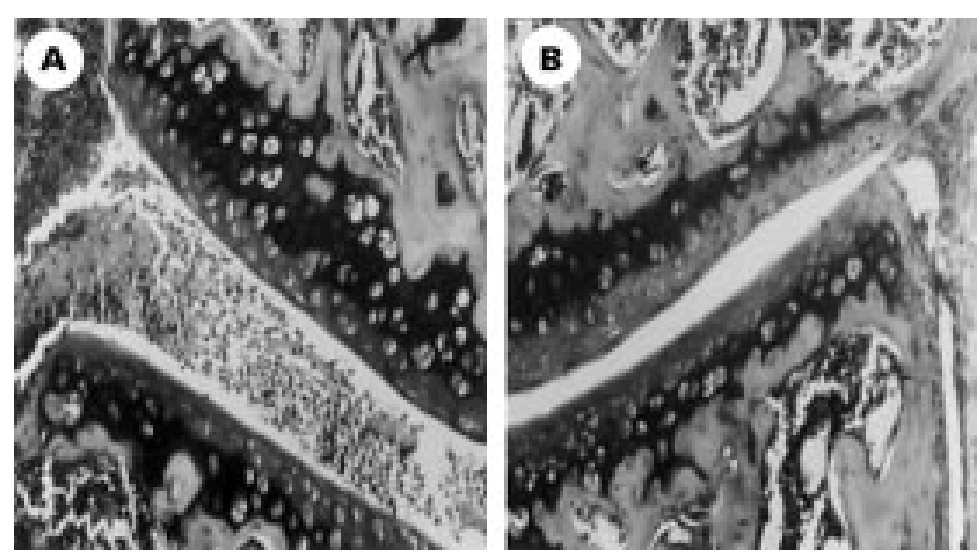

Figure 5 Cellular infiltrate is markedly reduced in $S C W$ arthritis (day 7) in TNFa -/mice (B). However, the Safranin $O$ staining shows that there is considerable loss of proteoglycans (reduced staining) in both control $(A)$ and TNF-/- $(B)$. again underlining that $\mathrm{TNF} \alpha$ and IL1 have separate activities.

SCW ARTHRITIS IN TNF $\alpha$ AND IL1 $\beta$ KNOCKOUT MICE

To substantiate uncoupling of mediator involvement in swelling and cartilage metabolism, and to exclude that the observed $\mathrm{TNF} \alpha$ independence of IL1 production and action were not attributable to inadequate $\mathrm{TNF} \alpha$ blocking, the impact of SCW arthritis was studied in TNF $\alpha$ and IL1 $\beta$ knockout mice. As SCW arthritis is not an immune driven model, the immunological impairment of the $\mathrm{TNF} \alpha$ knockout mice does not limit the analysis of this model. The IL1 $\beta$ knockout mouse is not impaired and shows a normal phenotype, with good delayed hypersensitivity responses to protein antigens as well as normal LPS induced inflammation with expected levels of circulating IL1, IL6 and TNF. ${ }^{36}$ When SCW arthritis is induced in $\mathrm{TNF} \alpha$ knockouts, joint swelling is fully reduced (fig 4), late synovial infiltrate (day 7) is markedly reduced, but cartilage proteoglycan loss was hardly diminished (fig 5). In fact, the observations are in line with data obtained with $\mathrm{TNF} \alpha$ blocking, and underline that cartilage damage can occur in the presence of limited amounts of cellular infiltration. ${ }^{36}$ In sharp contrast, joint swelling was not reduced in IL1 $\beta$ knockout mice (fig 4), yet late infiltrate was dimished and cartilage damage was highly reduced (fig 6 ).

Of great interest, additional studies were done in TNF knockout mice, knocked in with membrane bound form of TNF $(\mathrm{mTNF} \alpha)$ and kindly provided to us by George Kollias. It was shown that swelling was fully restored (fig 4). Recently it was demonstrated that arthritis could be induced by transgenic overexpression of transmembrane $\mathrm{TNF}^{37}$ elegantly showing that soluble $\mathrm{TNF} \alpha$ is not needed to get full expression of arthritis. The present study identifies that also during a normal triggering process with SCW, $\mathrm{mTNF} \alpha$ is capable of initiating full blown joint swelling. In addition it was found that not only joint swelling was fully restored but also that cellular infiltration was normalised. Preliminary studies with selective TNF receptor knockouts suggest that the effect on joint swelling runs through the P75 TNF receptor.

TNF $\alpha$ INDEPENDENT PRODUCTION OF IL1 $\beta$

A crucial element in the uncoupling of TNF $\alpha$ and IL $1 \beta$ driven events is the independent production of IL1 $\beta$. To substantiate this we isolated synovial tissue specimens at three and six hours after SCW induction in TNFa deficient mice and measured IL1 levels in the tissue washouts. In controls, IL1 $\beta$ production was already high at three hours and further increased with $30 \%$ at six hours. In $\mathrm{TNF} \alpha-/-$ mice there was a slight reduction in IL1 $\beta$ levels $(20 \%)$ at three hours, suggesting that some of the initial IL1 $\beta$ production occurs in a TNF $\alpha$ dependent fashion. However, at six hours no significant difference is seen anymore and full amounts of IL1 $\beta$ (2 ng per knee joint specimen) are produced in control and $\mathrm{TNF} \alpha$ 


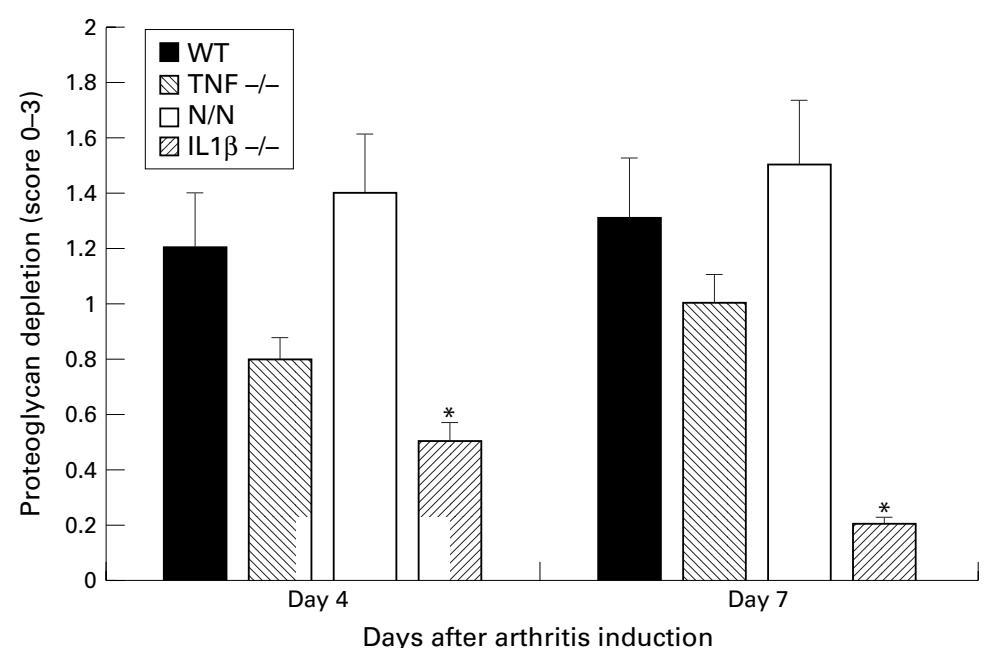

Figure 6 Proteoglycan depletion as measured on histological sections (see fig 5) stained with Safranin $O$ at days 4 and 7 after induction of $S C W$ arthritis. Scoring is semiquantitative on a scale of $0-3$. Note the significant reduction of depletion $\left({ }^{\star} p<0.01\right)$ only in IL1 $\beta-/-$ mice.

-/- mice, apparently through a $\mathrm{TNF} \alpha$ independent pathway. ${ }^{36}$ These findings are fully compatible with the progression of cartilage proteoglycan loss in $\mathrm{TNF} \alpha-/-$ mice.

\section{Chronic relapsing SCW arthritis}

The limited role of $\mathrm{TNF} \alpha$ described so far in tissue pathology in SCW arthritis relates to subacute arthritis. To bring the model more close to the clinical situation, we next evaluated the cytokine interplay in a model of chronic relapsing arthritis. In earlier studies in the mouse it was shown that a chronic, antigen induced arthritis can be flared with tiny amounts of antigen, when the joint displays local hyperreactivity by retained antigen specific $\mathrm{T}$ cells in the chronic infiltrate. ${ }^{38}$ Anti-IL1 treatment appeared effective in such $\mathrm{T}$ cell driven flares and caused marked reduction of cartilage damage. ${ }^{39}$ Apart from antigen specific rechallenge, such a joint is also highly sensitive to flares induced by cytokines, such as TNF and IL1. In fact, it suggests that any nonspecific inflammatory insult, with concomitant release of proinflammatory cytokines, may flare

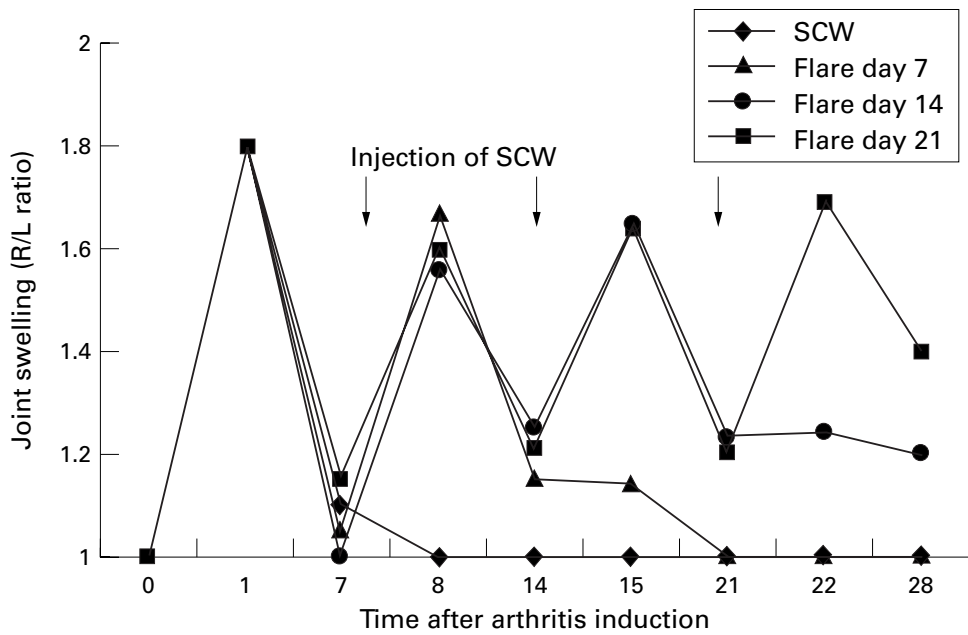

Figure 7 Chronic relapsing $S C W$ arthritis induced by repeated injection of $S C W$ fragments in the knee joint. Four groups of mice were flared either at day 7, days 7,14 or days 7,14,21. Chronicity increases after every rechallenge. a chronic arthritis, through reactivation of the retained macrophages. ${ }^{40}$ It underlines that an arthritis may start with an antigen specific (auto)immune event, but can be sustained by rather non-specific triggering processes.

Also in the model of murine SCW arthritis, flares can be induced at sites of smouldering arthritis by rechallenge with small amounts of SCW. An example of repeated flaring, with weekly rechallenge intervals is depicted in figure 7. It shows that acute joint swelling is noted after every rechallenge, but it also demonstrates that the remaining, smouldering arthritis is brought to a higher level and is getting more and more severe. Intriguingly, each flare remained $\mathrm{TNF} \alpha$ sensitive in terms of joint swelling, as identified by consistent suppression when TNF soluble receptors are given shortly before the flares. However, the chronic cellular infiltrate remains and advanced cartilage damage is not significantly reduced. In contrast, major protection against ongoing cartilage damage is achieved with anti-IL1 $\beta$ antibodies. Increasing effect was also seen on the swelling, probably linked to the sustained effect on the chronic infiltrate (see below). Of interest, Makarov et al showed in a similar model in rats that arthritis could be attenuated when primary synoviocytes were transduced in culture with retroviral IL1 ra and then engrafted in the ankle joints before reactivation of arthritis at that site. ${ }^{41}$

We performed repeated flare studies also in the cytokine knockout mice. Joint swelling was still significantly reduced after the fourth SCW challenge in $\mathrm{TNF} \alpha$ deficient mice. When the model was evaluated in IL1 $\beta$ deficient mice, impressive reduction of cartilage damage was seen. In fact, hardly any erosion was noted, whereas this was abundant in the control and the $\mathrm{TNF} \alpha$ knockout mice (fig 8, fig 9). Of great interest, also the chronic synovial infiltrate was profoundly reduced in the IL $1 \beta$ deficient mice. It does suggest that the repeated flare reactions make the cellular process in the synovial tissue more and more an IL1 $\beta$ dependent phenomenon, and this suppression will contribute to reduction of subsequent flares. A contributing factor in this suppression might be that chronicity of inflammation by repeated SCW rechallenge is in part sustained by cartilage molecules released from the damaged tissue and that this contributing factor is high in normal and $\mathrm{TNF} \alpha$ deficient mice, but is almost lacking in IL $1 \beta$ deficient mice, because of early arrest of the damaging process. Further analysis of the cellular process is at present under study, to identify the relative role of macrophage and $\mathrm{T}$ cell driven elements in the propagation and tissue destruction. This includes the evaluation of the potential role of $\mathrm{T}$ cell and macrophage associated cytokines IL12, IL15 and IL17 in the chronic stage.

Earlier work in TNF-/- and IL1 $\beta-/-$ mice have identified differential effects, dependent on the type and stage of process studied. Cytokine production induced by LPS appeared essentially intact in $\mathrm{TNF} \alpha-/-$ mice. However, these mice show little or no initial effect on injection of heat killed corynebacte- 


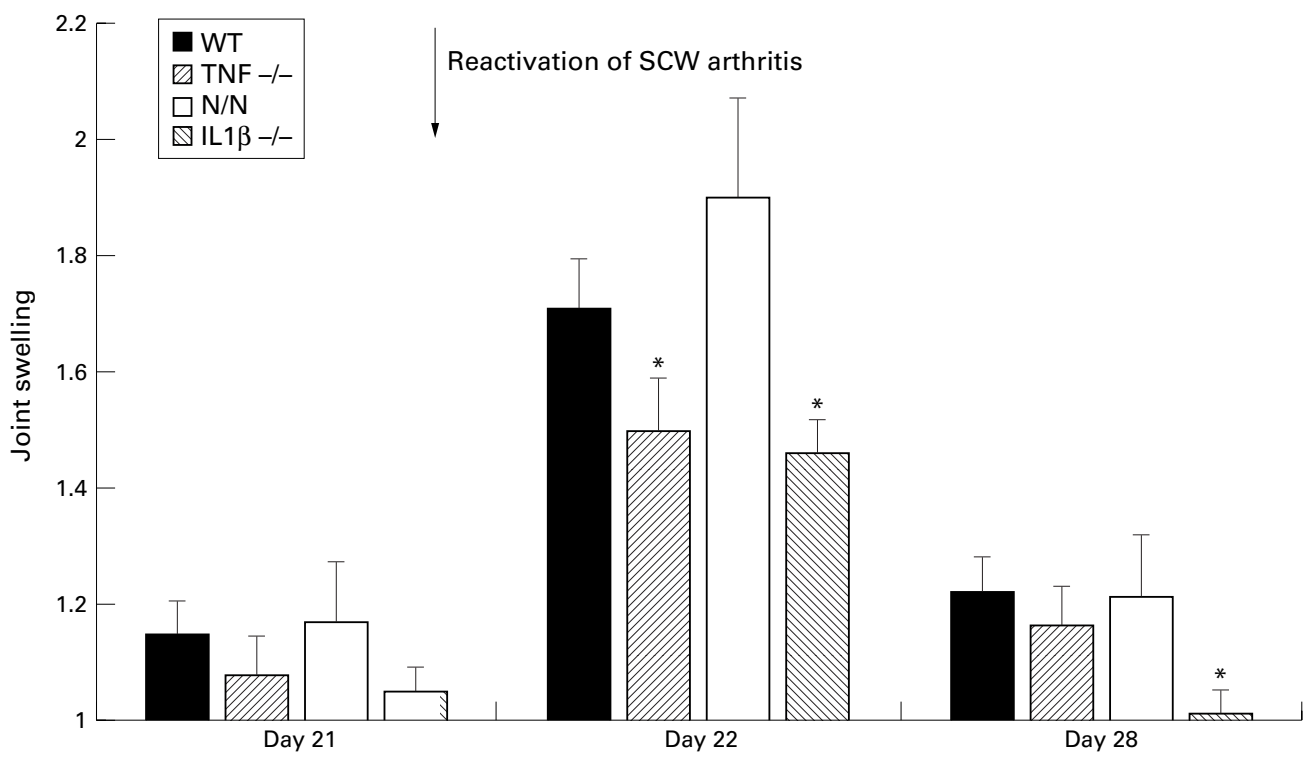

Figure 8 Experiments described under figure 7 were performed in the various cytokine-/- mice in the repeated flare protocol (days 7,14,21). Note that arthritis is roughly similar at day 21. The fourth injection of SCW fragments at day 21 caused a major flare, showing still some TNFa dependency, but also note IL1 $\beta$ dependency at that stage $\left({ }^{\star} p<0.01\right.$, compared with relative control strains).
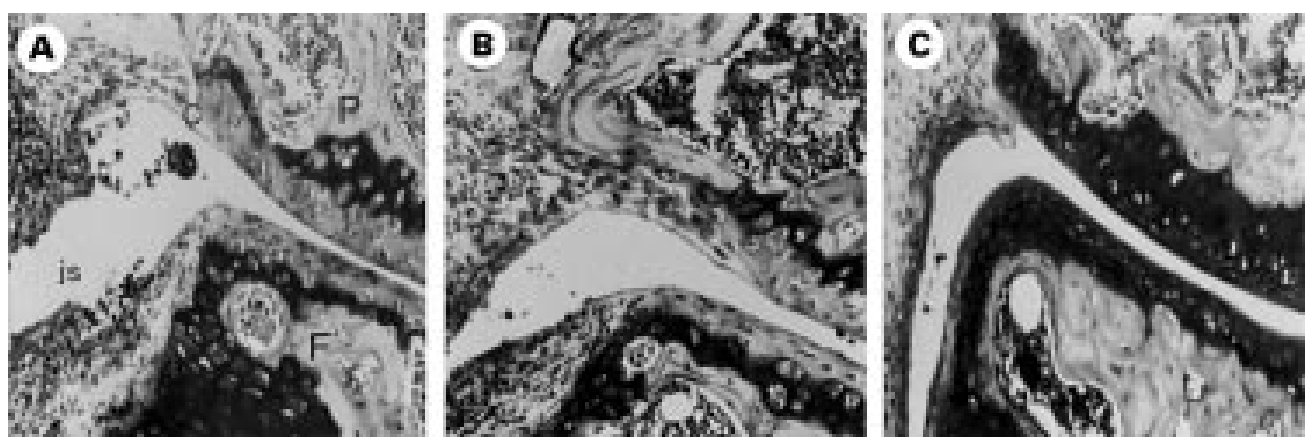

Figure 9 Histological examination of the knee at day 28 of relapsing $S C W$ arthritis (see figure 8). Safranin $O$ staining shows loss of proteoglycans from the cartilage surface layer in the controls $(A)$ and the $T N F a-/-m i c e(B)$. In contrast, IL1 $\beta$-/- mice (C) show major protection against proteoglycan loss, but also display markedly reduced infiltration.

rium parvum, but then develop a vigorous disorganised inflammatory response, suggesting that TNF has an essential homeostatic role in limiting inflammation. ${ }^{42}$ This fits with our observations with SCW fragments in TNF-/mice, in that we tend to lose TNF dependency on repeated flaring. In fact, the continued absence of $\mathrm{TNF} \alpha$ might limit the homeostatic role of $\mathrm{TNF} \alpha$ in apoptosis, indirectly causing exaggeration of cellular infiltration driven by other mediators. It would argue that care must be taken with complete blockage of TNF $\alpha$ in the clinical situation. On the other hand, IL1 seems not to be required for normal development and homeostasis, and reduced inflammatory responses are seen in IL $1 \beta-/-$ mice, type I receptor deficient mice and ICE deficient mice. ${ }^{43}{ }^{44}$ Remarkably, IL1 $\beta$ seems to control apoptosis of inflammatory neutrophils ${ }^{45}$ and this action might contribute to the marked reduction of late cellular infiltrate in the joint, as observed in our studies.

\section{Concluding remarks}

The above studies suggest potential uncoupling of joint swelling and ongoing cartilage destruction, being separate activities of $\mathrm{TNF} \alpha$ and IL1. Although it cannot be excluded at present that the triggering process in human synovial tissue is different, the claim of $\mathrm{TNF} \alpha$ being the driving force of IL1 production, and therefore being the key target in RA, must be viewed with care. Given the pivotal role of IL1 in amplifying late synovial infiltrate and cartilage destruction, omission of proper IL1 blocking might have considerable consequences for joint damage. Studies in other models, such as antigen induced arthritis, also identify that IL1 is not necessarily a crucial factor in early inflammation and initial proteoglycan loss, but is a pivotal factor in erosive cartilage destruction. ${ }^{46-48}$ Of interest, IL1 $\beta$ is a powerful stimulant to drive cell-cell interaction in the synovial tissue and to stimulate production of destructive enzymes. Membrane bound cytokines play a crucial part in this process. ${ }^{49}$

The above studies imply that IL1 always is the major destructive cytokine, but can be an important factor in the synovial inflammation in chronic stages of the process as well. This argues that IL1 would be a pivotal therapeutic target anyway. So far, this broad profile, with a role in inflammation as well, is not supported by observations of IL1 directed treatment in 
RA patients; suggestive proof is only obtained for a role in erosions. ${ }^{5}$ Whether this argues that inflammatory elements of the RA process are different from aspects of the various models remains to be identified. Current clinical studies are hampered by the lack of high quality IL1 neutralising antibodies and the poor pharmacokinetics of IL1 ra and overlooking of IL1 dependent processes by inadequate blocking cannot be excluded at present.

The alternative approach of direct IL1 neutralisation would be to block an upstream mediator, which is generating IL1 production. This is what is attempted with the anti-TNF $\alpha$ directed treatment in RA patients. The basis for this approach is the claim that in human $\mathrm{RA}, \mathrm{TNF} \alpha$ is the driving force of IL1 in the synovial tissue. ${ }^{50}$ These are old observations with neutralising anti-TNF antibodies and cytokine production in pieces of RA synovial tissue in vitro, and additional support from similar findings in follow up studies of other groups is unfortunately lacking so far.

Samples from early stages of RA are now becoming available through arthroscopic biopsy specimens and blind small needle biopsy specimens. TNF and IL1 are not always found and mRNA expression of these cytokines does occur uncoupled. ${ }^{51}$ Immunostainings also identify variabe patterns in different RA patients. ${ }^{52}$ It is the impression from our own biopsy specimens that large variation exists in $\mathrm{TNF} \alpha$ and IL 1 immunolocalisation patterns in such samples from various RA patients. Moreover, our preliminary observations in biopsy specimens from RA patients, treated with fully humanised anti-TNF $\alpha$ antibodies, could not identify significant IL1 reduction in synovial cells. On the other hand, it is clear that the systemic anti-TNF $\alpha$ treatment does reduce IL1 mRNA in leucocytes in the circulation in most patients and provides impressive, symptomatic relief. Further studies are awaited to clarify the identity of the synovial reaction and the individual cytokine interplay in various RA patients. It is expected that we are dealing with a heterogeneous process, asking for tailor made treatment. For the time being, a double hit approach, touching both $\mathrm{TNF} \alpha$ and $\operatorname{IL} 1 \beta$ seems warranted.

1 Firestein GS, Zvaifler NJ. How important are T cells in chronic rheumatoid synovitis. Arthritis Rheum 1990;33:768-73.

2 Feldmann M, Brennan F, Maini RN. Role of cytokines in rheumatoid arthritis. Annu Rev Immunol 1996;14:397440 .

3 Arend WP, Dayer JM. Inhibition of the production and effects of IL-1 and TNFI in RA. Arthritis Rheum 1995;38: effects of

4 Keffer J, Probert L, Cazlaris H, et al. Transgenic mice expressing human tumor necrosis factor: A predictive genetic model of arthritis. EMBO J 1993;10:4025-31.

5 Bresnihan B, Alvaro-Garcia JM, Cobby M, et al. Treatment of rheumatoid arthritis with recombinant human IL-1 receptor antogonist. Arthritis Rheum 1998;41:2196-204.

6 Saklatvala J. Tumor necrosis factor a stimulates resorption and inhibits synthesis of protetoglycan in cartilage. Nature 1986;322:547-9

7 Van de Loo AAJ, van den Berg WB. Effects of murine recombinant IL-1 on synovial joints in mice: Measurement of patellar cartilage metabolism and joint inflammation. of patellar cartilage metabolism and
Ann Rheum Dis 1990;49:238-45.

8 Henderson B, Pettipher ER. Arthritogenic actions of Henderson B, Pettipher ER. Arthritogenic actions of
recombinant IL-1 and TNFI in the rabbit; evidence for synergistic interactions between cytokines in vivo. Clin Exp synergistic interactions betwe
Immunol 1989;75:306-10.
9 Chabaud M, Durand JM, Buchs N, et al. Human IL-17-A $T$ cell derived proinflammatory cytokine produced by the T cell derived proinflammatory cytokine produced by the
rheumatoid synovium. Arthritis Rheum 1999;42:963-70. 10 Ghivizzani SC, Kang R, Georgescu HI, et al. Constitutive intra-articular expression of human IL-1 $\beta$ following gene transfer to rabbit synovium produces all major pathologies of human rheumatoid arthritis. J Immunol 1997;159: 3604-12.

11 Niki Y, Yadmada H, Kikuchi T, Takaishi H, Fujikawa K, Tada N. Membrane associated IL-1 contributes to chronic synovitis in human IL-1ra transgenic mice. Arthritis Rheum 1998;41:S212.

12 Probert L, Plows D, Kontogeorgos G, Kollias G. The type I IL-1 receptor acts in series with TNFI to induce arthritis in TNFI transgenic mice. Eur J Immunol 1995;25:1794-7.

13 Kontoyiannis D, Pasparakis M, Pizarro TT, Cominelli F Kollias G. Impaired on/off regulation of TNf biosynthesis in mice lacking TNF AU-rich elements:implications for joint and gut associated immunopathologies. Immunity joint and gut as

14 Mauri C, Williams RO, Walmsley M, Feldmann M. Relationship between Th1/Th2 cytokine patterns and the arthritogenic response in collagen induced arthritis. Eur J Immunol 1996;26:1511-18.

15 Joosten LAB, Lubberts E, Durez P, et al. Role of IL-4 and IL-10 in murine collagen-induced arthritis: protective effect of IL-4 and IL-10 treatment on cartilage destruction. Arthritis Rheum 1997;40:249-60.

16 van den berg WB, Joosten LAB. Murine collagen induced arthritis. In: Morgan DW, Marshall LA, eds. In vivo models of inflammation. Basle:Birkhauser Verlag, 1999:51-71.

17 Joosten LAB, Lubberts E, Helsen MMA, van den Berg WB: Dual role of IL-12 in early and late stages of murine collagual role of IL-12 in early and late stages of murine co

18 Marinova -Mutafchieva L, Williams RO, Mason LJ, et al. Dynamics of proinflammatory cytokine expression in the joints of mice with collagen induced arthritis. Clin Exp Immunol 1997;107:507-12.

19 Williams RO, Feldmann M, Maini RN. Anti-TNF ameliorates joint disease in murine collagen induced arthritis. Proc Natl Acad Sci USA 1992;89:9784-8.

20 Wooley PH, Dutcher J, Widmer MB, Gillis S. Influence of a recombinant human soluble $\mathrm{TNF}$ receptor $\mathrm{Fc}$ fusion protein on type II collagen induced arthritis in mice. J Immunol 1993;151:6602-7.

21 Van den Berg WB, Joosten LAB, Helsen MMA, van de Loo AAJ. Amelioration of established murine collagen induced arthritis with anti-IL-1 treatment. Clin Exp Immunol 1994;95:237-43.

22 Joosten LAB, Helsen MMA, van de Loo FAJ, van den Berg WB. Anticytokine treatment of established type II collageninduced arthritis in DBA/1 mice: a comparative study using anti-TNFI, anti-IL-1

$23 \mathrm{Ku} \mathrm{G}$, Faust T, Lauffer LL, Livingston DJ, Harding MW. IL-1 $\beta$ converting enzyme inhibition blocks progression of type II collagen induced arthritis in mice. Cytokine 1996;8:377-86.

24 Bendele A, McAbee T, Senello G, Frazier J, Chlipapa E, McCabe D. Efficacy of sustained blood levels of IL-1ra in animal models of arthritis. Comparison of efficacy in animal models with human clinical data. Arthritis Rheum 1999;42:498-506.

25 Bakker AC, Joosten LAB, Arntz OJ, et al. Prevention of murine collagen-induced arthritis in the knee and ipsilateral paw by local expression of human IL-1ra protein in the knee. Arthritis Rheum 1997;40:893-900.

26 Pasparakis M, Alexopoulou L, Episkopou V, Kollias G. Immune and inflammatory responses in TNFI-deficient mice: A critical requirement for TNFI in the formation of primary B cell follicles, follicular dendritic cell networks primary B cell follicles, follicular dendritic cell networks
and germinal centers, and in the maturation of the humoral and germinal centers, and in the maturation of the hum

27 Alexopoulou L, Pasparakis M, Kollias G. Complementation of lymphotoxin alpha knockout mice with TNf expressing ransgenes rectifies defective splenic structure and fucntion. J Exp Med 1998;17:745-54.

28 Mori L, Iselin S, De Libero G, Lesslauer W. Attenuation of collagen-induced arthritis in $55-\mathrm{kDa}$ TNF receptor type 1 (TNFR1)-IgG1-treated and TNFR1-deficient mice. J Immunol 1996;157:3178-82.

29 van Lent PLEM, van de Loo FAJ, Holthuysen AEM, van den Bersselaar LAM, Vermeer H, van den Berg WB. Major role for IL- 1 but not for TNF in early cartilage damage in immune complex arthritis in mice. J Rheumatol 1995;22: 2250-8.

30 Joosten LAB, Helsen MMA, Saxne T, van de Loo FAJ, Heinegard D, van den Berg WB. IL-1I, J blockade prevents cartilage and bone destruction in murine type II collageninduced arthritis, whereas TNFJ blockade only ameliorates joint inflammation. J Immunol (in press).

31 Kassiotis G, Pasparakis M, Kollias G, Probert L. TNF accelerates the onset but does not alter the incidence and severity of myelin basic protein induced experimental autopimmune encephalomyelitis. Eur J Immunol 1999;29: 774-80

32 Van de Loo AAJ, Joosten LAB, van Lent PLEM, Arntz OJ, van den Berg WB. Role of interleukin-1, tumor necrosis factor I and interleukin-6 in cartilage proteoglycan metabolism and destruction. Effect of in situ cytokine blocking in murine antigen- and zymosan-induced arthritis. Arthritis Rheum 1995;38:164-72.

33 Lubberts E, Joosten LAB, Helsen MMA, van den Berg WB. Regulatory role of IL-10 in joint inflammation and 
cartilage destruction in murine streptococcal cell wall (SCW) arthritis. More therapeutic benefit with IL-4/IL-10 combination therapy than
Cytokine 1998;10:361-9.

34 Kuiper S, Joosten LAB, Bendele AM, et al. Different roles of TNFI and IL-1 in murine streptococcal cell wall arthritis. Cytokine 1998;10:690-702

35 Zheng H, Fletcher D, Kozak W, et al. Resistance to fever induction and impaired acute-phase response in IL-1Jdeficient mice. Immunity 1995;3:9-19.

36 Van den Berg WB, Joosten LAB, Kollias G, van de Loo FAJ, Helsen MMA. TNF independent role of IL-1J in cartilage destruction in SCW arthritis: evidence form TNFI and IL-1J deficient mice. J Clin Invest (in press).

37 Georgopoulos S, Plows D, Kollias G. Transmembrane TNF is sufficient to induce localized tissue toxity and chronic inflammatory arthritis in transgenic mice. J Inflamm 1996; inflammat $86-97$

38 Lens JW, van den Berg WB, van de Putte LBA, Zwarts WA Flare-up of antigen induced arthritis in mice after challenge with intravenous antigen: kinetic of antigen in the challenge with intravenous antigen: kinetic of antigen in the
circulation and localization of antigen in the arthritic and circulation and localization of antigen in the arthritic

39 Van de Loo AAJ, Arntz OJ, Bakker AC, van Lent PLEM, Jacobs MJM, van den Berg WB. Role of interleukin-1 in antigen-induced exacerbations of murine arthritis. Am J Pathol 1995;146:239-49.

40 Van de Loo AAJ, Arntz OJ, van den Berg WB. Flare-up of experimental arthritis in mice with murine recombinan IL-1. Clin Exp Immunol 1992;87:196-202.

41 Makarov SS, Olsen JC, Johnston WN, et al. Suppression of experimental arthritis by gene transfer of IL-1 ra cDNA. Proc Natl Acad Sci USA 1996;93:402-6.

42 Marino MW, Dunn A, Grail D, et al. Charaacterization of TNF-deficient mice. Proc Natl Acad Sci USA 1997;94: 8093-8.

43 Fantuzzi G, Ku G, Harding MW, et al. Response to local inflammation in IL-1b converting enzyme deficient mice. J Immunol 1997;158:1818-24.
44 Labow M, Shuster D, Zetterstrom M, et al. Absence of IL-1 signaling and reduced inflammatory response in IL-1 type I receptor deficient mice. J Immunol 1997;159:2452-61.

45 William R, Watson G, Rotstein OD, Parodo J, Bitar R, Marshall JC. The IL-1b converting enzyme (caspase-1) inhibits apoptosis of inflammatory neutrophils through activation of IL-1b. J Immunol 1998;161:957-62.

46 Van Meurs JBJ, van Lent PLEM, Holthuysen AEM, Singer II, Bayne EK, van den Berg WB. Kinetics of aggrecanase and metalloproteinase induced neoepitopes in various stages of cartilage destruction in murine arthritis. Arthritis Rheum 1999;42:1128-39.

47 Van Meurs JBJ, van Lent PLEM, Singer II, Bayne EK, van de Loo FAJ, van den Berg WB. IL-1 ra prevents expression of the metalloproteinase-generated neoepitope VDIPEN in antigen-induced arthritis. Arthritis Rheum 1998;41:64756.

48 Van Meurs JBJ, van Lent PLEM, Holthuysen AEM, et al. Cleavage of aggrecan at Asn341-Phe342 site coincides with the initiation of collagen damage in murine antigeninduced arthritis: A pivotal role for stromelysin-1 in MMP activity. Arthritis Rheum (in press).

49 Burger D, Rezzonico R, Li JM, et al. Imbalance between interstitial collagenase and TIMP1 in synoviocytes and fibroblasts upon direct contact with stimulated $\mathrm{T}$ lymphocytes. Involvement of membrane associated cytokine. phocytes. Involvement of membrane

50 Brennan FM, Chantry D, Jackson A, Maini RN, Feldmann $M$. Inhibitory effect of TNFI antibodies on synovial cell IL-1 production in rheumatoid arthritis. Lancet 1989;ii: 244-7.

51 Deleuran B. Cytokines in RA; localization in arthritic joint tissue and regulation in vitro. Scand J Rheumaol 1996;25 (suppl 104):1-38.

52 Kirkham B, Portek I, Lee CS, et al. Intrarticular variability of synovial membrane histology, immunohistology, and cytokine mRNA expression in patients with rheumatoid arthritis. J Rheumatol 1999;25:777-84. 